\title{
Yatırımcıların Hisse Getirisi Beklentileri Üzerinde Geçmişin Gölgesi: Geçmiş Ekstrapolasyonu*
}

\author{
İbrahim Emre KARAA**
}

\begin{abstract}
$\ddot{O} Z$
Etkin piyasalar hipotezi, yatırımcıların rasyonel beklentileri olacă̆ını ve rasyonel kararlar vereceklerini ileri sürmektedir. Davranışsal finans çalışmalarında ise psikolojik yanlılıklar ve hevristikler sebebiyle yatırımclların sistematik olarak rasyonaliteden saptıkları belirlenmiştir. Araştırmada öncelikle yatırımclların getiri beklentilerini oluştururken rasyonaliteden uzaklaşarak aşırı güven ve iyimserlik içinde olduklarına ilişkin kanıtlar sunulmaktadır. İkinci olarak geçmiş ekstrapolasyonu; yatırımciların hisse getiri beklentileri üzerinde kendi geçmiş hisse getirilerinin ve geçmiş finansal göstergelerin etkisi ile belirlenmiştir. Üçüncü olarak, yatırımcıların geçmiş hisse getirileri, hisse beklentileri üzerinde çok etkili olduğunda bu etki hiçbir finansal gösterge değişkeni ile azalmamaktadır. Dolayısıyla yatırımcıların geleneksel teorinin öngördüğü şekilde rasyonel olmadıkları bulgulanmıştır.
\end{abstract}

Anahtar Kelimeler: Getiri beklentileri, Aşırl güven, Finansal göstergeler

JEL Sinıflandırması: G02

\section{The Shadow of Past on the Investors' Stock Return Expectations: Past Extrapolation}

\begin{abstract}
Efficient markets hypothesis suggests that investors form their expectations and make decisions rationally. Psychological biases and heuristics cause systematic outrays from rationality has been documented in the field of behavioural finance. In this research, first I documented some evidence about investors' overconfidence and overoptimism on forming their stock return expectations. Second, I presented past extrapolation on stock returns by the relations between investor's past stock returns and outdate financial indicators. Third, investors form their future stock expectations relying on past returns mostly and financial indicators some. Last, the very strong effect of past returns does not diminish by any financial type of indicator on stock return expectations. As a result, investors are not rational as traditional theory suggests.
\end{abstract}

Key Words: Return expectations, overconfidence, overoptimism

JEL Classification: G02

\section{GİRIŞ}

Geleneksel Finans Teorileri, esasen yatırımcıların nasıl davrandıkları ile ilgilenmeme eğilimindedir ve öğrenme ve arbitrajın davranış etkilerini yok edeceği savunulmaktadır. Bu teorilerin esas aldığı yatırımcıların davranışları rasyoneldir ve tahmin edilebilirdir, iyi tanımlanmış durağan tercihleri vardır, alternatifler arasından seçimini beklenen çıktılara göre yapmaktadır ve sürekli faydasını maksimize edecek kararlar verir. Yatırımcıların verdikleri yanlış

\footnotetext{
${ }^{*}$ Doktora tezinden üretilmiştir

** Yrd. Doç. Dr., Manisa Celal Bayar Üniversitesi, Uygulamalı Bilimler Yüksekokulu. emre.karaa@cbu.edu.tr (Makale Gönderim Tarihi: 28.01.2016 / Yayına Kabul Tarihi: 21.03.2017)
} 
kararlar onların yeterince sofistike olmamaları ile açıklanmış, farklı işlemlerin piyasay1 etkileyemeyeceği sadece arbitrajörler için firsat oluşturabilecekleri ve zamanla da piyasadan tasfiye olacakları düşünülmüştür. Yatırımcılar beklentilerini erişilebilir tüm bilgiyi elde ederek oluşturmaktadır. Piyasaların bir saat mükemmelliğinde çalıştı̆̆ gerektiği gibi olduğu tezine karşı birçok ampirik kanıtlar üretilmiş bulunmaktadır. Bu kanıtlar, davranışsal yaklaşımları ortaya çıkarmıştır.

Davranışsal yaklaşımların önem kazanmasıyla birlikte, arbitajın sınırlı ve riskli olduğu, riskten kaçındıkları, sadece bilgisiz yatırımcıların değil, profesyonel yatırımcılar da dâhil birçok yatırımcının sistematik olarak Bayes kurallarını ihlal ettikleri ortaya çıkmıştır.

Yatırımcıların rasyonel beklentilerini oluştururken geçmişte elde ettiklerinden hareket etmemeleri beklenir. Başka bir deyişle geçmiş getirilerinin, getiri beklentisi üzerindeki etkisinin "sıfır" olması gerekir. Eğer bir etki varsa, bu durum bir ekstrapolasyondur çünkü getiri beklentilerinin hesaplanmasında, mevcut gözlem ve usullerin ötesinde dışsal bir değişkenle ilgisi var demektir. Vissing-Jorgensen (2003) yatırımcıların geçmiş getirilerinin hisse getiri beklentileri üzerindeki etkisini bulgulamıştır. Buna göre, yatırımcı beklentilerinin hisse alımlarını etkilediğini, beklentileri anlamının hisse fiyatlarını anlamaya yardımcı olacağı ileri sürülmektedir.

Benzer şekilde yatırımcıların geçmiş finansal verileri de baz alarak da beklenti oluşturmaması beklenir. Esasen profesyonel olmayan yatırımcılar ikinci elden, herkesin ulaşabildiği verilere ulaşabilmektedirler. Yatırımcılar eğer beklentilerini geçmiş getirileri ve geçmişteki temel finansal göstergelerden hareketle oluşturuyorlarsa, o zaman hangi geçmiş göstergeleri, hangi ağırlıkta kullandıklarının belirlenmesi beklentileri önceden buna dayanarak tahmin etmek de değerli olacaktır.

Eğer geçmişte elde ettikleri getirilerin bir etkisi yoksa bu takdirde geçmişte kaybedenler ile kazananların farklı beklentilerinin olmaması gerekir ancak, yatırımcıların aşırı iyimserliklerini besleyen kendine yorma yanlılıkları, bilgi illüzyonu ve kontrol illüzyonu gibi unsurların beklentileri etkilediği bilinmektedir.

Araştırmamızda ilk olarak, aşırı güven araştırılmış; geçmişte kazanan ve geçmişte kaybedenlerin portföy beklentileri değerlendirilmiştir. İkinci olarak, Vissing-Jorgensen'in kullandığ $\mathrm{UBS} /$ Gallup veri setinden daha geniş bir zaman dilimindeki aynı veri seti kullanılarak öncelikle ilişkinin varlığı yeniden test edilmiştir. Üçüncü olarak, temel göstergeler kabul edilen geçmiş piyasa getirileri, kâr payı fiyat oranı, fiyat kazanç oranı, faiz, tüketici güven endeksinin yatırımcıların hisse beklentileri üzerindeki etkisi araştırılmıştır. Dördüncü olarak, hisse getiri beklentileri üzerinde etkili olduğu bulgulanan geçmiş getirilerin etkisinin yanında geçmiş temel göstergelerin etkisi araştırılmıştır. 


\section{I. İLGILİ LITERATÜR}

\section{A. Așırı Güven ve Așırı İyimserlik}

De Long vd., (1991), Kyle ve Wang (1997), Benos (1998), Caballe ve Sakovics (2003), Daniel, Hirshleifer ve Subramanyam (1998, 2001), Odean (1998), ve Gervais ve Odean (2001) yatırımcıların aşırı güvenli oldukları varsayımına dayanan teorik modeller geliştirmişlerdir. $\mathrm{Bu}$ modellere göre, aşırı güvenli yatırımcılar rasyonel yatırımcılara göre aşırı işlem yapmakta, finansal varlıkların değerleriyle ilgili kendi bilgi ve kabiliyetlerini abartmakta, en iyi hisseyi seçebileceklerine, en uygun zamanda giriş ve çıkış yapabileceklerine inanmaktadırlar. Bir varlıkla ilgili değer biçilirken, kendi değerlendirmelerinin isabetli olma olasılığının diğerlerinden yüksek olduğunu düşünmektedirler (Barber ve Odean, 2002).

Bilgi illüzyonu, aşırı güveni kısmen oluşturan unsurlardan biridir. Bilgi illüzyonu, daha fazla bilgi elde edildiğinde, tahminlerinin doğruluğuna daha çok inanma eğilimidir. Bir diğer deyişle, bir konu hakkında daha fazla bilgi elde eden kişinin, kararları daha isabetli olacaktır. Doğruluk, isabetlilik şansının gerçeklerden daha yüksek olduğunu düşünürler. Böylelikle elde ettikleri ilave bilgilerle insanlar tahminleri konusunda kendilerine daha çok güvenir olurlar (Nofsinger, 2010).

Her ne kadar kullanılan bilgiler tahminleri güçlendirici bir unsur olsa da, aşırı güveni daha çok güçlendirmektedir. Elliot, Hodge ve Jackson (2008) yaptıkları deneyde katılımcılara kolejler arası futbol müsabakalarında kimin kazanacağı, takımların hangi aralıkta puan alacakları ve tahminin ne kadar isabetli olduğu sorulmuştur. İkinci etapta, önceki sonuçları gösterir istatistikler vermiş ve yeniden sorulmuştur. İstatistiksel bilgiler verildiğinde, katılımcılar tahminlerini ve kendi doğruluk derecelerini yenilemişlerdir. Daha fazla bilgi verildikçe, tahminlerindeki isabet derecesi düşmüştür, diğer yandan da kendilerine olan güvenleri giderek artmıştır.

Bireysel yatırımcılar, zihinsel kısa yollar anlamına gelen hevristikleri profesyonel yatırımcılardan daha çok sergilemektedir. De Bondt (1998) de 45 yatırımc1 ile bir deney gerçekleştirmiştir. Buna göre, 45 yatırımcı "Yatırımc1 Kulübü" nün organize ettiği bir konferansa katılmışlardır. Yatırımcıların 2/3'ü erkektir, ortalama yatırımcı yaşı $58^{\prime}$ dir, 18 senedir yatırım piyasasındadırlar ve \$310.000'lık portföyleri vardır ve bunun \%72'si hisse senedinden oluşmaktadır. Her hafta, günde yedi saat yatırımlarını düşünmektedirler ve her hafta bir televizyon programını seyretmektedirler. Yirmi hafta sonunda, yatırımcılardan hem Dow Jones, hem de kendi portföyleri için gelecek tahmini yapmaları istenmiştir. Sonuçta, yatırımcılar kendi portföyleriyle ilgili aşırı derecede iyimserdirler ama Dow Jones için o kadar iyimser olmadıkları bulgulanmıştır. İkinci bulgu, fiyatlardaki değişmeleri gördükçe şaşkınlık sergilemişlerdir çünkü aşırı güven duygusu içindedirler. Üçüncü bulgu, hisse fiyatları ile ilgili tahminlerinde demirleme etkisi ve geçmiş performansın izleri görülmektedir. Kendi tuttukları hisselerle ilgili bir yükseliş trendi olduğunda yapılacak pek bir 
şey olmadığını azalışta ise çok seçenek olduğunu düşünmektedirler. Son olarak, piyasa ile hisselerin ardışı yürüyüşlerinin derecesini hesaba katmamaktadırlar, başka bir deyişle betayı hesaplamamaktadırlar. Buna göre, bireysel yatırımcılar aşırı iyimserdirler, aşırı güven duymaktadırlar, riskle getiri arasındaki pozitif ilişkiyi anlamamış görünmektedirler.

İyimserlik, kişilerin inançlarını ve yargılarını çarpıtır. İyimserlik iki şekilde ortaya çıkmaktadır; birincisi hisse ile ilgili karar verirken yeterince eleştiri yapmamaktadırlar, ikincisi hisselerle ilgili kötü haberler geldiğinde bunları umursamamaktadırlar. İyimser olanlar hisse alımı yaparken kötümser olanlar sadece seyretmektedir, dolayısıyla fiyatlar yukarı gittikçe kötümserlerin kötümserlikleri artar (Nofsinger, 2010).

Aracı firmalardaki profesyonellerin piyasada motivasyonun düşük olduğu bir ortamda dahi endeks tahminlerinde iyimserlik gözlenmiştir (örn. Darrough ve Russel, 2002). Eames, Glover ve Kennedy (2000), getiri tahminlerdeki iyimserliğin sebebi olarak şuursuzca favori hisse tavsiyelerini görmektedir. Elton, Gruber ve Gültekin (1984), analistlerin iyi iş çıkartan şirketler hakkında aşırı iyimser olduklarını ortaya koymuşlardır. Piyasalar yukarıdayken yatıımcılar iyimser, diplerdeyken çok kötümserdirler. Yatırımcılar iyimser (kötümser) olduğunda piyasalar yukarıda (aşağıda) olmaktadır. Bu genel duyarlılık, getirileri tahminlemekte kullanılabilir kılmaktadır (Nofsinger, 2010).

De Bondt ve Thaler aşırı güvenin temsil yanlılığına da dayandığını düşünmektedir (Shefrin, 2002). Bir olayın yargısını vermekte, ana kütlenin bazı temel özelliklerinin ya da süreçlerinin benzerlik göstermesi durumunda ihtimale dayanan bir temsil fikri oluşmaktadır. İnsanlara bir konu ya da olayla ilgili olarak olasılıkları değerlendirmeleri istendiğinde, A şayet bir B sürecine aitse, olasılıklar A'nın B'yi temsiliyet derecesine göre hesaplanmaktadır. İnsanlar belirsizliğin olduğu ortamlarda, benzer kalıplara bakma eğilimindedirler ve bu kalıpların kendini tekrarlayacağını düşünürler.

$\mathrm{Bu}$ hevristik sahiplerinin bilinmeyen bir olayın olasıllı̆ını; (i) bir anakütlenin temel özellikleri arasındaki benzerliklerle,(ii) geçirilen sürecin dikkat çeken özellikleri yansıttığını belgelemiştir. En önemli bulgulardan biri de insanların tamamen tesadüfî seyreden olaylarda belli kalıplar, trendler görebilmiş olmalarıdır (Tversky ve Kahneman, 1974). Temsil edilebilirlik yanlılığının etkilerini, , göstermiştir. Yatırımcıların geçmişte kaybeden hisse senetleriyle ilgili aşırı kötümser oldukları ve kazanlarla ilgili olarak ise aşırı iyimser olduklarını ve bunun da bir temsil edilebilirlik yanlılığı olduğunu zira hevristik kaynaklı yanlılıkların temel değerden saptırdığını gözlemlenmiştir (De Bondt ve Thaler, 1985). Geçmişte kaybettiren hisseler değerinin altında fiyatlanmış olmakta, kazandıranlar ise aşırı fiyatlanmaktadır.

\section{B. Geçmiş Tecrübelerin Etkisi}

İnsanlar sistematik olarak Bayes kuralını ve olasılık teorilerinin öngörülerinin sonuçlarını ihlal etmektedir. Örneğin insanlar, sıklıkla belirsiz olan gelecekteki olayları tahmin etmeye çalışırken, çok küçük çok da geri gitmeyen bir 
veri setinden faydalanırlar ve gelecekteki durumu bu geniş resimde bir yerlere yerleştirmeye çalışırlar. Geçmiş olayların temsil yeteneği olduğunu düşünürler (Kahneman ve Riepe, 1998).

Temsil yanlılığında bireyler genellikle geçmişte yaşanan olayların da şans eseri olduğunu düşünmez ve adeta bir modelmiş gibi ele alırlar adeta bir bilgisayara kaydedilmiş gibi geçmiş kayıtlar olayların tanımlanması için kalıplar oluşturulması gibi gerektiğinde ilk başvuruyu kendi kayıtlarına yaparlar ancak bu durum yatırımcıları doğru kararlardan uzaklaştırabilir. Sekiz önemli strateji uzmanına bir önceki yıldan, bir sonraki yıl için Dow endeksi tahminleri alınmıştır ve yedisi beklentilerini oluştururken tıpkı geçen seneki gibi olacağını düşünmüştür (Rublin, 1997).

Mevcudiyet hevristiğini de değerlendirmekte fayda vardır. Bu hevristik, her gün çok sayıda edinilen tecrübeyi açıklamaktadır (Rothman ve Hardin, 1997; Thaler, 1987). Bir kişi, olasılığı ya da sıklığı hesaplarken zihninde örnekler ve ilişkiler canlanır. Yakın zamanda gerçekleşen olaylar daha kolay hatırlanır ve çok sayıda örnek varsa bu daha iyi ve hızlı akla gelmektedir. Bunun tersi, sıklığı az olan ve daha uzun bir zaman önce olanlar, daha güç hatırlanır. Her ikisi birleştiğinde yani, hem yakın zamanda hem de sıklığı yüksek olan olaylar, daha hızla ve iyi bir şekilde hatırlanır (Tversky ve Kahneman, 1973).

Kısa dönemli geçmişe bakarak, örneğin bazı firmaların aşırı kazançlarını göz önüne alarak asla fazla yükselmeyecek olan bazı hisseleri aşırı fiyatlayabilirler. $\mathrm{Bu}$ türden aşırı reaksiyonlar, gelecekteki kârlarını azaltacaktır zira geçmiş büyüme oranları aynen devam etmediği gibi piyasada fiyat düzeltmeleri yapılacaktır. Ancak, Grahamn ve Harvey (2003), CFO'lara uygulanmış bir anketle getirilerle ilgili seviyeler ve uzun-kısa dönem dalgalanmalarını analiz etmişlerdir. Yakın geçmişteki getirilerin gelecek bir yılı tahminlemede etkili olduğunu ancak daha uzun dönem beklentileri söz konusu olduğunda ise çeşitlenme gösterdiğini ortaya koymuşlardır.

Yatırımcılar kazançları realize etmeye kayıpları realize etmekten daha heveslidir. Yanlış pozisyon (disposition effect) etkisinden söz edilebilir. Kayıplar başladığında hisseleri elden çıkarmakta gecikirler çünkü genellikle kıyaslamayı geçmişte satın aldığı fiyata göre yapmaktadırlar.

Amromin ve Sharpe (2008), yatırımciların gelecekle ilgili beklentilerinin geçmiş tecrübelere dayandığını bir kez daha test etmiş ve geçmişten etkilendikleri sonucuna ulaşmıştır. Fisher ve Statman (2002), Vissing-Jorgensen (2003), bu araştırmada üzerinde çalışılmış olan veri seti ile çalışmışlar ve yatırımcıların gelecekle ilgili tahminlerinin kendi geçmiş tecrübelerinden etkilendiğini-ki bu tecrübe geçmiş getirileridir- ortaya koymuşlar ve bilişsel yanlılıklar bulmuşlardır.

\section{Getiri Beklentileri}

İnsanlar tahmin yapacakları zaman, ellerindeki kanıtlara aşırı dikkat sarfederken, istatistiksel ağırlıklarına hiç dikkat etmemektedirler (Griffin ve Tversky, 1992). Varlık fiyatlamasıyla ilgili olarak hem psikolojik hem de pür rasyonel teorilere göre getiriler tahmin edilebilir niteliktedir ancak getiri 
konusunda inançlardaki heterojen yap1 tartışma konusu olmuştur. Finans literatüründe bu konu genellikle yok kabul edilmiş ya da önemsenmemiştir. CAPM'in (Sermaye Varlıkları Değerleme Modeli) orijinal versiyonunda herkesin aynı beklentide olacağı varsayılmış (Sharpe, 1964; Lintner, 1965), tartışmalar üzerine beklentilerin heterojen yapısının modeli etkilemeyeceği söylenmiştir (Sharpe, 1970; Lintner, 1969).

Dominitz ve Manski (2003; 2004), Michigan anketini Haziran 2002 ve Mayıs 2003 arasında değerlendirmişler, pozitif nominal hisse getirisi beklentilerinin kişilerin cinsiyetine, yaşına ve eğitim durumuna göre sistematik olarak değiştiğini göstermişler, bireylerin inançlarının zaman içinde istikrarlı olduğunu da bulguları arasında göstermişlerdir. Daha sonra Dominitz ve Manski (2009) genişletilmiş bir veri seti ile tekrar aynı sonuçlara ulaşmıştır.

Profesyonel yatırımcılar genellikle piyasaları çeşitli veri kaynaklarından takip eder ve kararları ve beklentilerini bunlara göre oluşturur. Yatırımcılar kararlarını alırken, tipik olarak tüm piyasa trendlerini, farklı endüstrileri ve işletmeleri izler. Bireysel yatırımcılardan ilgi duyanlar ise genellikle bu bilgileri ikinci elden alır. Tüketici güveni anketlerinde insanlara yatırımları, onları etkileyen faktörler, hisse piyasalarındaki gelişmeler karşısındaki beklentileri sorulmaktadır. Yatırımcılar gelecekteki hisse fiyatlarını kestirmeyi sağlayacak göstergeler peşindedir. Teknik analizler bunun bir örneğidir. Bilimsel yaklaşım ise yatırımcı beklentilerini ölçen göstergelerdir. $\mathrm{Bu}$ göstergeler tüketici güven endeksine (Consumer Confidence Index) benzer şekilde oluşturulmuştur. Michigan Üniversitesinden George Kantona, Tüketici duyarlıllğı endeksini (Consumer Sentiment Index) geliştirmiştir ki geniş bir kabul görmüş ve kısa vadede tüketici alımlarının iyi bir tahmincisi olmuştur.

Manski (2004), beklentilerin nasıl oluştuğunu bulmak için kişilerin çevrelerinde neyi fark ettiklerini ve yeni bilgileri nasıl bir süreçten geçirdiklerini açıklayan yoğun araştırmalara ihtiyaç vardır demektedir. Daha sonraki çalışmasında Dominitz ve Manski (2011), Michigan üniversitesindeki ve Wisconsin üniversitesindeki veri setlerinden yatırımc1 beklentilerini analiz ederek, endeksler arasındaki kovaryansları ve aktüel hisse fiyatlarındaki gelişmeleri değerlendirdikten sonra, bu kadar geniş veriler olmasına rağmen beklentilerin nasıl oluştuğunu anlamaya yetmediğini söylemektedir. Kişilerin bu tür bilgileri nasıl işlediklerini, süreçlerini anlamak için küçük örneklem gruplarıyla yapılacak uzun görüşmeler gerekli olduğu (Dominitz ve Manski, 2011) sonucuna varmışlardır.

\section{METODOLOJí}

\section{A. Veri Setleri}

Araştırmada kullanılan veri setleri; UBS/Gallup Investor Optimism (Yatırımc1 İyimserliği) anketi, S\&P500 Toplam Getirileri, S\&P 500 getirilerinin düzenlenmesiyle oluşturulmuş Robert Shiller'in kazanç ve kâr payı oranları veri seti, Michigan Consumer Sentiment (Tüketici Güven Endeksi) anketi veri setidir. 
Ubs/Gallup Yatırımc1 İyimserliği anketi (Investor Optimism Survey) 1998-2002 yılları arasında yatırımcıların hisse beklentilerini ölçmektedir. Bu ankette, a) geçen bir yıl getirileri b) gelecek bir yil getiri beklentisi c) piyasanın bir yılda ne getireceği d) Gelecek on yılda piyasanın ne getireceğine ilişkin veriler derlenmiştir.

Michigan Üniversitesinin Yatırımc1 Anketi(Investor Survey) ABD hanehalkını temsil eden bir örneklem grubuna uygulanmaktadır. Bunun için, bir kişinin en azından 25.000\$ tutarında hisse senedi ya da yatırım ortaklığı fonunda parası olması aranmaktadır. Bu anket sonucunda iki endeks ortaya konmuştur; Yatırımc1 Duyarlılığı endeksi(Investor Sentiment Index) ve Yatırımcı beklentileri endeksi(Investor Expectations Index).

\subsection{UBS/Gallup Yatırımcı İyimserliği Veri Seti Değişkenleri}

Tüm değişkenler tablosu Ek 1'de verilmiştir ancak ayrı veri setlerinden elde edilen değişkenlerin hesaplamalarına dair açıklamalar aşağıdadır.

Epast; "Geçen 12 ay sonunda bütün portföyünüzden yüzde ne oranda getiri elde ettiniz?" anket sorusuna dayanmaktadır.

Erown"; "Önümüzdeki 12 ay için portföyünüzden beklediğiniz getirinin oranı nedir?" anket sorusuna dayanmaktadır.

Erstck ; " "Genel anlamda Borsayı düşünerek, sizce hisse senedi piyasaları önümüzdeki 12 ayda yatırımcılarına ne kadar kazandırır?" anket sorusuna dayanmaktadır.

Her ay için -95 'in altındaki ve +95 'in üzerindeki veriler atılmıştır. $\mathrm{Bu}$ yöntem Gallup tarafindan da izlenmiştir. Ayrıca 2000 yılından önce $\% 100$ ve üzerindeki cevapların nasıl kodlandığı açık değildir.

\section{Üretilen değişkenler:}

wl_past: Geçmişlerinde kazanıp kazanmadıklarını tespit etmek için oluşturulmuştur. İkili değişkendir. Kazananlar ve Kaybedenler olarak sinıflandırılmıştır.

lhexp: Geçmişte kaybetmiş olup da gelecek için iyimser olanların gösterildiği değişkendir.

\footnotetext{
${ }^{1}$ Ankette bu soru 1998'de 12 numaralı sorudur, daha sonra Eylül 1998'le Aralık 2001 arasında 15. soru olmuştur. Ocak 2002 yllından itibaren 10. soru olmuş ve sonuna kadar yani 2007 Ekim ayına kadar değişmemiş̧ir. Ocak 2000 yılından itibaren ankette anketörden negatif ya da pozitif yorum alması istenmiştir. Örneğin; 2001 Aralık ayına kadar, aralık ayı dâhil 15a sorusu, 2002 Ocaktan itibaren 11. soru şöyle başlar: "Anketör: Pozitif ya da negatif mi diye sormayın. Şayet emin değilseniz, o durumda doğrulatın. Genel kural olarak cevaplayan (eksi ya da negatif) demediği müddetçe pozitif olduğunu varsaymalısınız"

${ }^{2}$ Ankette, 1998 Mayıs'ında bu soru 13. soru, daha sonra 1998 Eylül'ünden 2001 Aralık ayına kadar 16. sorudur. 2002 Ocak'ında 12. soru olmuş ve son tarihi olan 2003 Nisanına kadar öylece kalmıştır. Ocak 2000 yılından itibaren ankette anketörden negatif ya da pozitif yorum alması istenmiştir. Örneğin; 2001 Aralık ayına kadar, aralık ayı dâhil 16a sorusu, 2002 Ocaktan itibaren 13. soru şöyle başlar: "Anketör: Pozitif ya da negatif mi diye sormayın. Şayet emin değilseniz, o durumda doğrulatın. Genel kural olarak cevaplayan (eksi ya da negatif) demediği müddetçe pozitif olduğunu varsaymalısınız” Ayrıca, Erstck değişkenini oluştururken ilave bir değişken daha kullanılmıştır ancak bu sadece 2000 yılının Ocak ayından itibaren uygulanması mümkün olabilmiştir. 1998 ve 1999 yıllarının hep pozitif olduğu varsayılmıştır.
} 
whexp: Geçmişte kazanmış olup, gelecek konusunda da iyimser olanların gösterildiği değişkendir.

$p t \_s t c k$ : Hisse beklentileri, risksiz oranın üzerinde olanlarca oluşturulmuş değişkendir.

Erstck_Lrf: Hisse beklentileri, geçmişte kaybeden yatırımcıların, beklentileri bir y1l önceki risksiz oranın altında olanlarca oluşturulmuş değişkendir.

Erstck_Wrf: Hisse beklentileri, geçmişte kazanan yatırımcıların, beklentileri bir yıl önceki risksiz oranın üzerinde ve bu seneki beklentileri risksiz oranın üzerinde olanlarca oluşturulmuş değişkendir.

Erown_Lrf: Portföy beklentileri, geçmişte kaybeden yatırımcıların, beklentileri bir yıl önceki risksiz oranın altında olanlarca oluşturulmuş değişkendir.

Erown_Wrf: Portföy beklentileri, geçmişte kazanan yatırımcıların, beklentileri bir yıl önceki risksiz oran oranının üzerinde ve bu seneki beklentileri risksiz oranın üzerinde olanlarca oluşturulmuş değişkendir.

\subsection{S\&P500 Toplam Getiriler Değişkenleri}

$\mathrm{Bu}$ araştırmada, S\&P500 endeksindeki aylık getiriler iki yönteme göre hesaplanmıştır;

Birinci yöntem: "rtn_prior12m", "twoyravret", "threeyravret", "fouryravret", "rtn_prior3m" değişkenleri aşağıdaki şekilde hesaplanmıştır:

rtn_prior12m: Bir önceki aydan başlayarak 12 ay öncesinden itibaren getiriler hesaplanmıştır. Yatırımcı iyimserliği anketinin bir ay öncesinden alınmas1 gibi. Bu peryoddaki t değeri, t-12 ile t-1 (dâhil) peryodu aralığında, S\&P500 Toplam Getiriler endeksindeki oransal değişmeyi temsil etmektedir. Örneğin: 2003 Ocak ayı için, 2002 Ocak ayı ile 2001 Aralık ayları (dâhil), rtn_prior $12 \mathrm{~m}$ şu şekilde hesaplanmıştır:

$$
\text { rtn_prior } 12 m_{\text {malex }}=\frac{\text { S\&P endeksi Aralnk 2002-S\&P endeksi Ocak } 2002}{\text { S\&P endeksi Ocak } 2002}
$$

twoyravret: Anketteki aya göre önceki iki ylllk getirilerin aritmetik ortalaması alınmak suretiyle oluşturulmuştur. Örneğin anketteki ay 2003 Ocak ayı ise; twoyravret aşağıdaki şekilde hesaplanmıştır:

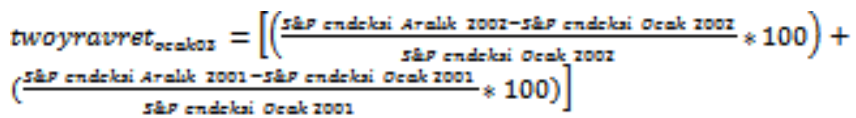

12

"threeyravret", üç y1llık getirilerden, "fouryravret", dört yıllık getirilerden, "rtn_prior3m" değişkeni 3 ay öncesinin aritmetik ortalaması alınarak "twoyravret" için kullanılan yöntemle oluşturulmuştur. 
Íkinci Yöntem: returnma12, returnma24, returnma36 ve returnma48 değişkenleri aşağıdaki gibi hesaplanmıştır:

Öncelikle bir getiri değişkeni olan "rtn12m" oluşturulmuştur. "rtn_prior12m" değişkenindeki aynı yöntem (bkz. Birinci Yöntem) kullanılmıştır ancak, fark1 "rtn12m" değişkeninin t değeri, t-11 ile t değerlerini içine alacak şekilde oluşturulmuş olmasıdır. Örneğin, 2003 Ocak ayı için önceki 12 ay, 2002 Ocak ile 2002 Aralık ayları dâhil olmak üzere "rtn12 $m_{\text {Aralk } 02 \text { " şu şekilde }}$ hesaplanmıştır:

$$
r \operatorname{rn} 12 m_{\text {Aralluar }}=\frac{(\text { S\&P endeksi Aralık 2002 }- \text { S\&P endeksi Ocak 2002) }}{\text { S\&P endeksi Ocak } 2002} \leqslant 100
$$

Daha sonra ise 12. Aya gelindiğinde aynı örneğe devamla, 2002 Aralık ayı için hesaplamaya, 2001 Ocak ayı dâhil edilerek hesaplanmıştır. Nihayetinde değişkenler aşağıdaki şekilde hesaplanmıştır:

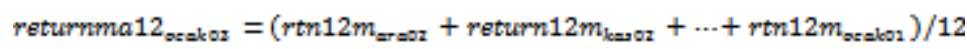

Sirasıyla "returnma24", "returnma36" ve "returnma48" değişkenleri elde edilmiştir.

\subsection{S\&P Robert Shiller Değişkenleri}

"Divyld" ve "Earnyld" Değişkenleri, Yatırımcı İyimserliği verilerine uygunluk göstermesi bakımından; 1998 Mayıs, Eylül, Kasım, 1999 yılı Mayıs ayı hariç olmak üzere 1999 yılının Şubat ayından itibaren aylık verilerin tamamı 2007 Ekim ayına kadar alınmıştır. Robert Shiller, "Irrational Exuberance" kitabında bu verileri kullanmıştır, kitap 2000 ve 2005 yıllarında basılmıştır, sonraki verilere yazarın internet sayfasından ulaşılmıştır.

En temel göstergelerden biri olan Kazanç/Fiyat oranı ya da tersi olan Fiyat/Kazanç oranı karar verme açısından en önemli araçlardan biri olarak her zaman değerlendirilmiştir. Kâr duyuruları profesyonel ve profesyonel olmayan yatırımcılar tarafından dikkate alınır çünkü kazançlar doğrudan doğruya getiri ile ilişkilidir. Hatta yatırımcıların bütün dikkatlerini hisse başına kazanca verdikleri gözlemlenmiştir (Beaver, 1989). Yatay kesit ve zaman serileri prosedürleri geliştirildiğinde, kazançların getirileri açıklamaktaki gücü artmıştır (Dumontier ve Labelle, 1998).

"earnyld1m", “earnyld3m", “earnyld12m" değişkenleri, Yatırımcı İyimserliği verilerine uygunluk göstermesi bakımından; 1998 Mayıs, Eylül, Kasım, 1999 yılı Mayıs ayı hariç olmak üzere 1999 yılının Şubat ayından itibaren aylık verilerin tamamı 2007 Ekim ayına kadar alınmıştır. Earnyld değişkenleri tamamen kazanç verim oranlarıdır(P/E). "earnyld1m" oranı, 1 önceki aydan başlatılarak; "earnyld3m", önceki üç ayın aritmetik ortalaması alınarak, "earnyld $12 \mathrm{~m}$ " ise önceki on iki ayın aritmetik ortalaması alınarak sete ilave edilmiştir. 
"divyld1m", “divyld3m", "divyld12m” değişkenleri, gerçek fiyatlarla yapılan düzeltmeden sonra elde edilen kâr payı değerinin fiyata olan oranını(D/P) göstermektedir. "divyld1m" kar payı değişkeni, 1 önceki aydan başlatılarak; "divyld3m", önceki üç ayın aritmetik ortalaması alınarak, "divyld12m" ise önceki on iki ayın aritmetik ortalaması alınarak sete ilave edilmiştir.

\subsection{Michigan Tüketici Duyarlılık Endeksi Değişkenleri}

Amromin ve Sharpe (2008) çalışmalarında, yatırımcıların kısa ya da orta vadeli makroekonomik şartların hesaplanmasını sevdikleri ve bu şekilde yüksek getiriler bekleme eğiliminde olduklarını bulmuşlardır. "CSI Değiş̧keni”, Yatırımcı İyimserliği verilerine uygunluk göstermesi bakımından 1998 Mayıs, Eylül, Kasım, 1999 yılı Mayıs ayı hariç olmak üzere 1999 yılının Şubat ayından itibaren aylık verilerin tamamı 2007 Ekim ayına kadar alınmıştır. Data setinde uyumluluk göstermesi bakımından 1 ay öncesinden başlatılarak alınmıştır.

\subsection{Faiz Oranları}

"Intrate" değişkeni, Yatırımcı İyimserliği verilerine uygunluk göstermesi bakımından 1998 Mayıs, Eylül, Kasım, 1999 yılı Mayıs ayı hariç olmak üzere 1999 yılının Şubat ayından itibaren aylık verilerin tamamı 2007 Ekim ayına kadar alınmışıır. Aylık faiz, bankaların kısa dönemde verdikleri borçların ortalamasından elde edilmiştir. ABD"de faaliyet gösteren yerel 25 ticari bankadan veriler alınmıştır. Federal Reserve Bank"in internet sitesinde tarihsel verilere ulaşmak mümkündür. (http://www.federalreserve.gov/econresdata/release

\section{B. Araştırmanın Hipotezleri}

Araştırmada aşağıdaki hipotezleri test etmek için T-testi, F-Testi, Regresyon ve Çok Değişkenli regresyonlar, Çoklu Doğrusal Bağlantı (Multicollinearity) testleri kullanılmıştır. Araştırmada aşağıdaki hipotezler test edilmiştir:

$\boldsymbol{H}_{\mathbf{1}}$ : Geçmişte kaybeden yatırımcıların portföy getiri beklentileriyle, kazanan yatırımcıların portföy getiri beklentileri arasında anlamlı bir fark vardır.

$\boldsymbol{H}_{2}$ : Geçmişte kaybeden yatırımcıların hisse senedi getiri beklentileriyle, kazanan yatırımcıların hisse senedi getiri beklentileri arasında anlamlı bir fark vardir.

$\boldsymbol{H}_{3}$ : Geçmişte kaybeden iyimser yatırımcıların getiri beklentileriyle, geçmişte kazanan iyimser yatırımcıların getiri beklentileri arasında anlamlı bir fark vardir.

\section{ANALIZLER}

\section{A. Geçmişteki Getirilerin Etkisi-Hipotez Testleri}

$\boldsymbol{H}_{1, a}$ : Geçmişte kaybeden yatırımcıların portföy getiri beklentileriyle, kazanan yatırımcıların portföy beklentileri arasında anlamlı bir fark vardir.

$\boldsymbol{H}_{\mathbf{1}, \mathbf{0}}$ : Geçmişte kaybeden yatırımcıların portföy beklentileriyle, kazanan yatırımcıların portföy beklentileri arasında anlamlı bir fark yoktur. 
Tablo 1. Eşit Varyaslarla İki Örneklem T-Testi

\begin{tabular}{lllllll}
\hline Değişken & Gözlem & Ortalama & Std. Hata & Std. Sapma & \multicolumn{2}{c}{ [\%95 Güven Aralı̆̆ ] } \\
\hline Erown_Lrf & 9708 & -0.44 & 0.0696 & 6.861 & -0.58 & -0.31 \\
Erown_Wrf & 69951 & 1.212 & 0.0402 & 106.343 & 1.204 & 1.22 \\
\hline Kombine & 79659 & 1.059 & 0.0391 & 1.104 & 1.051 & 1.066 \\
Fark & & -1.257 & 0.111 & & -1.279 & -1.235 \\
\hline
\end{tabular}

fark=ort(Erown_Lrf-ort(Erown_Wrf) Ha:fark $>0 ; \operatorname{Pr}(T>t)=1$

T-testi sonuçlarına göre $H_{1, a}$ kabul edilmiş, $H_{1,0}$ reddedilmiştir. Geçmişte kazananların portföy beklentileriyle geçmişte kaybeden yatırımcıların portföy beklentileri arasında fark vardır.

$\boldsymbol{H}_{2, a}$ : Geçmişte kaybeden yatırımcıların hisse beklentileriyle, kazanan yatırımcıların hisse senedi getiri beklentileri arasında anlamlı bir fark vardır.

$\boldsymbol{H}_{\mathbf{2}, \mathbf{0}}$ : Geçmişte kaybeden yatırımcıların hisse senedi getiri beklentileriyle, kazanan yatırımcıların hisse senedi getiri beklentileri arasında anlamlı bir fark yoktur.

Tablo 2. Eşit Varyaslarla İki Örneklem T-Testi

\begin{tabular}{lllllll}
\hline Değişken & Gözlem & Ortalama & Std. Hata & Std. Sapma & \multicolumn{2}{c}{ [\%95 Güven Aralığ1] } \\
\hline Erstck_Lrf & 10243 & 563.746 & 0.082429 & 8.432 .473 & 5.475 .882 & 5.799 .037 \\
Erstck_Wrf & 32588 & 1.148 .421 & 0.061737 & 1.114 .478 & 1.136 .321 & 1.018 .857 \\
\hline Kombine & 42831 & 1.1008 .597 & 0.052347 & 108.335 & 9.983 .365 & 1.018 .857 \\
Fark & & -5.846752 & 0.119422 & & -6.08082 & -5.612682 \\
\hline \multicolumn{2}{c}{ fark=ort(Erstck_Lrf-ort(Erstck_Wrf) } & & \multicolumn{3}{c}{ Ha:fark>0; Pr(T>t)=1 }
\end{tabular}

T-testi sonuçlarına göre $H_{2, a}$ kabul edilmiş, $H_{2,0}$ reddedilmiştir. Geçmişte kazananların hisse beklentileriyle geçmişte kaybeden yatırımcıların hisse beklentileri arasında fark vardır.

$\boldsymbol{H}_{3_{i} a}$ : Geçmişte kaybeden iyimser yatırımcıların getiri beklentileriyle, geçmişte kazanan iyimser yatırımcıların getiri beklentileri arasında anlamlı bir fark vardir.

$\boldsymbol{H}_{\mathbf{3}_{\mathbf{0}} \mathbf{0}}$ : Geçmişte kaybeden iyimser yatırımcıların getiri beklentileriyle, geçmişte kazanan iyimser yatırımcıların getiri beklentileri arasında anlamlı bir fark vardir.

Tablo 3. Eşit Varyaslarla İki Örneklem T-Testi

\begin{tabular}{lllllll}
\hline Değişken & Gözlem & Ortalama & Std. Hata & Std. Sapma & \multicolumn{2}{c}{ [\%95 Güven Aralı̆̆1] } \\
\hline lhexp & 8528 & 8.886 .304 & 0.085247 & 7.872 .321 & 8.669 .199 & 9.003 .409 \\
whexp & 55776 & 1.182 .198 & 0.043542 & 1.028 .334 & 1.173 .663 & 1.190 .732 \\
\hline Kombine & 64304 & 1.142 .602 & 0.039625 & 100.482 & 1.134 .835 & 1.150 .368 \\
Fark & & -2.985671 & 0.116238 & & -3.213497 & -2.757846 \\
\hline
\end{tabular}


T-testi sonuçlarına göre $H_{3, a}$ kabul edilmiş, $H_{3,0}$ reddedilmiştir. Geçmişte kazanan iyimser yatırımcıların beklentileri ile geçmişte kaybeden yatırımcıların beklentileri arasında önemli bir fark vardır.

\section{B. Hisse Getirileri Analizleri}

Hisse piyasasından getiri beklentileri ile geçmiş hisse beklentisi ve diğer faktörler ile tek tek alınarak yatay kesit (Erstck (YK)) ve ortalamalarla (Erstck(Ort)) regresyonu aşağıdaki özet tabloda gösterilmektedir. Tüm değişkenler için bulunan anlamlı sonuçlar sadece bir ay öncesinin kâr pay1 getirisinde yatay kesit ve ortalamalarda işaretin değiştiği görülmektedir.

Yatay kesit değişkenler ile iki model, ortalamalar ile bir model ileri sürülmüştür. Tüm değişkenlerin ele alınmış, farklı getiri yöntemleri sebebiyle iki ayrı grup değişkenleri ile \%1 anlam düzeyinde adımsal (stepwise) regresyon uygulanmıştır. \%1 anlam düzeyinin altında kalan değişkenler çıktığında Model 1 ve Model 2 yatay kesit için oluşturulmuştur. Tüm değişken ortalamaları ile yine adımsal (stepwise) regresyona tabi tutulmuş ve Model 3 belirlenmiştir. Herhangi çoklu doğrusal bağlantı (multicollinearity) sorunu yoktur.

Tablo 4. Hisse Piyasası Getiri Beklentisi ve Tüm Değişkenler Özet Regresyon Tablosu

\begin{tabular}{|c|c|c|c|c|c|c|}
\hline \multirow{2}{*}{$\begin{array}{l}\text { Hisse piyasası getiri beklentisi (Erstck)Tekli } \\
\text { Regresyonlar } \\
\text { Geçmiş Hisse Getirisi } \\
\end{array}$} & \multicolumn{2}{|c|}{ Erstck (YK) } & \multirow{2}{*}{$\begin{array}{l}\begin{array}{l}\text { R- } \\
\text { kare }\end{array} \\
0,186 \\
\end{array}$} & \multicolumn{2}{|c|}{ Erstck (Ort) } & \multirow{2}{*}{$\begin{array}{l}\begin{array}{l}\text { R- } \\
\text { kare }\end{array} \\
0.937 \\
\end{array}$} \\
\hline & $0,234 * * *$ & $(0,002)$ & & $0.334 * * *$ & $(0.012)$ & \\
\hline Bir ay öncesi fiyat-kârpayı oranı (divyld1m) & $-10,36 * * *$ & $(0,223)$ & 0,048 & $1,022 * * *$ & $(118.5)$ & 0.593 \\
\hline Üç ay öncesi fiyat-kârpayı oranı (divyld3m) & $-10,56 * * *$ & $(0,241)$ & 0,043 & $-1.044 * * *$ & (136.5) & 0.534 \\
\hline Oniki ay öncesi fiyat-kârpayı oranı(divyld12m) & $-8,212 * * *$ & $(0,335)$ & 0,014 & $-863.3^{* * * *}$ & $(247.8)$ & 0.192 \\
\hline Bir ay öncesi fiyat kazanç oran 1 (earnyld $1 \mathrm{~m}$ ) & $2,024 * * *$ & $(0,110)$ & 0,353 & $206.6^{* * * *}$ & $(84.73)$ & 0.104 \\
\hline Üç ay öncesi fiyat kazanç oranı(earnyld3m) & $2,390 * * *$ & $(0,114)$ & 0,364 & $241.1 * * *$ & $(86.22)$ & 0.133 \\
\hline Oniki ay öncesi fiyat kazanç oranı (earnyld12m) & $3,956 * * *$ & $(0,128)$ & 0,416 & $391.1 * * *$ & $(90.54)$ & 0.268 \\
\hline Tüketici Duyarlılık Endeksi (CSI) & $20,278 * * *$ & $(0,005)$ & 0,066 & $0.276^{* * * *}$ & $(0.019)$ & 0.804 \\
\hline Faiz Oranı (Intrate) & $1,298 * * *$ & $(0,027)$ & 0,049 & $1.276 * * *$ & $(0.143)$ & 0.608 \\
\hline Son 12 ay getiri ortalaması (returnma12) & $0,173 * * *$ & $(0,003)$ & 0,067 & $0.172 * * *$ & $(0.011)$ & 0.821 \\
\hline Son 24 ay getiri ortalaması (returnma24) & $0,190 * * *$ & $(0,003)$ & 0,069 & $0.189^{* * * *}$ & $(0.011)$ & 0.839 \\
\hline Son 36 ay getiri & $8,212 * * *$ & $(0,335)$ & 0,070 & $0.237 * * *$ & $(0.136)$ & 0.856 \\
\hline Son 48 ay getiri ortalaması (returnma48) & $0,303 * * *$ & $(0,005)$ & 0,067 & $0.3 * * *$ & $(0.019)$ & 0.82 \\
\hline 3 ay öncesinin getiri ortalaması ( $\mathrm{rtn}$ prior3m) & $0,256 * * *$ & $(0,008)$ & 0,019 & $0.248^{* * * *}$ & $(0.064)$ & 0.225 \\
\hline Öncesindeki 1 yıl getiri ortalaması $(\mathrm{rtn}$ prior $12 \mathrm{~m})$ & $0,157^{* * * *}$ & $(0,002)$ & 0,064 & $0.158^{* * * *}$ & $(0.011)$ & 0.785 \\
\hline Öncesindeki 2 yıl getiri ortalaması (twoyravret) & $0,174 * * *$ & $(0,003)$ & 0,067 & $0.175^{* * *}$ & $(0.011)$ & 0.828 \\
\hline Öncesindeki 3 yil getiri ortalaması (thereeyravret) & $0,202 * * *$ & $(0,003)$ & 0,068 & $0.202 * * *$ & $(0.012)$ & 0.827 \\
\hline Öncesindeki 4 yıl getiri ortalaması (fouryravret) & $0,247 * * *$ & $(0,004)$ & 0,066 & $0.247 * * *$ & $(0.017)$ & 0.803 \\
\hline Gözlemler (n) & 42,8 & & & 53 & & \\
\hline \multicolumn{7}{|c|}{ Standart hata parentezler içindedir, $* * * p<0,01 * * p<0,05 * p<0,1$} \\
\hline
\end{tabular}

Tüm değişkenlerin hisse getirisi beklentisiyle anlamlı ilişkisi vardır.

Fiyat-kâr payı oranlarının (D/P) negatif değerler aldığı, yani azaldıkça beklentileri arttırdığ 1 görülmektedir. Bunun anlamı, kâr payları arttıkça kapital kazancının azalacağı beklentisidir. Benzer durum faiz oranlarında da görülmektedir, faiz oranları düştüğünde firmaların daha uygun 
borçlanabilecekleri, buna bağlı olarak kârlılıklarının artacağı düşünülebilir. Merton(1973), göstermiştir ki, yatırım fırsatları, kâr payı oranlarının değişmesiyle zaman içinde değişmektedir yani, kâr payı oranı düştüğünde beklenen getiri düşer, kâr payı oranı yükseldiğinde beklentiler yükselir.

Tablo 5. Regresyon Modelleri Tablosu

\begin{tabular}{|c|c|c|c|c|c|c|}
\hline \multirow{2}{*}{$\begin{array}{l}\text { Hisse piyasası getiri beklentisi (Erstck) } \\
\text { Geçmiş Hisse Getirisi }\end{array}$} & \multicolumn{2}{|l|}{ Model 1} & \multicolumn{2}{|c|}{ Model 2} & \multicolumn{2}{|c|}{ Model 3} \\
\hline & $\begin{array}{l}0.204 * * \\
*\end{array}$ & $\begin{array}{l}(0.002 \\
9)\end{array}$ & $\begin{array}{l}0.206^{* *} \\
*\end{array}$ & $\begin{array}{l}(0.002 \\
9)\end{array}$ & $\begin{array}{l}0.477^{* *} \\
*\end{array}$ & $(0.0474$ \\
\hline Faiz Oranı (Intrate) & $\begin{array}{l}- \\
1.536 * * \\
*\end{array}$ & $(0.179$ & $\begin{array}{l}- \\
1.438 * * \\
*\end{array}$ & $(0.259$ & $\begin{array}{l}- \\
1.101 * *\end{array}$ & $(0.244)$ \\
\hline Tüketici Duyarlılık Endeksi (CSI) & $\begin{array}{l}0.0769 * \\
* *\end{array}$ & $\begin{array}{l}(0.020 \\
2)\end{array}$ & $\begin{array}{l}0.0545 * \\
* *\end{array}$ & $\begin{array}{l}(0.016 \\
5)\end{array}$ & & \\
\hline Bir ay öncesinin fiyat-kârpayı oranı (divyld1m) & $\begin{array}{l}- \\
3.127 * * \\
*\end{array}$ & $(0.832$ & & & & \\
\hline Üç ay öncesinin fiyat kazanç oranı(earnyld3m) & $\begin{array}{l}2.582 * * \\
*\end{array}$ & $\begin{array}{l}(0.442 \\
)^{2}\end{array}$ & & & $\begin{array}{l}225.3^{* *} \\
*\end{array}$ & $(60.91)$ \\
\hline Son 12 ay getiri ortalaması (returnma12) & $\begin{array}{l}- \\
0.089 * * \\
*\end{array}$ & $\begin{array}{l}(0.034 \\
1)\end{array}$ & & & $\begin{array}{l}- \\
0.191 * * \\
*\end{array}$ & )$^{(0.0412}$ \\
\hline Son 36 ay getiri ortalaması (returnma36) & $\begin{array}{l}0.268 * * \\
*\end{array}$ & $\begin{array}{l}(0.050 \\
4)\end{array}$ & & & $\begin{array}{l}0.258 * * \\
*\end{array}$ & )$^{(0.0580}$ \\
\hline $\begin{array}{l}\text { Oniki ay öncesinin fiyat-kârpayı } \\
\text { oranı(divyld } 12 \mathrm{~m} \text { ) }\end{array}$ & & & $\begin{array}{l}- \\
8.489 * * \\
*\end{array}$ & )$^{(1.235}$ & & \\
\hline Bir ay öncesinin fiyat kazanç oranı (earnyld1m) & & & $\begin{array}{l}1.406^{* *} \\
*\end{array}$ & $(0.342$ & & \\
\hline $\begin{array}{l}\text { Oniki ay öncesinin fiyat kazanç oranı } \\
\text { (earnyld12m) } \\
\text { Öncesindeki } 1 \text { yıl getiri ortalaması } \\
\text { (rtn_prior12m) } \\
\text { Öncesindeki } 2 \text { y1l getiri ortalaması (twoyravret) }\end{array}$ & & & $\begin{array}{l}1.15 * * * \\
0.0413 * \\
* * \\
0.0681 * \\
* *\end{array}$ & $\begin{array}{l}(0.329 \\
) \\
(0.009 \\
) \\
(0.013 \\
)\end{array}$ & & \\
\hline Gözlemler (n) & 35.818 & & 35.818 & & 53 & \\
\hline $\begin{array}{l}\text { R-Kare } \\
\text { Standart hata parentezler içindedir, } * * * \mathrm{p}<0,01\end{array}$ & $\begin{array}{l}0.197 \\
<0,05 *\end{array}$ & & 0.196 & & 0.962 & \\
\hline
\end{tabular}

Model 1'de ve Model 3'de son 12 ayın getiri ortalamas1 (returnma12) ile de negatif bir ilişki görülmektedir, yatırımcılar son on iki aydaki düşüşleri bir artış sinyali olarak yorumluyor olabilirler. Model 2'de ise durum böyle değildir, aksine son oniki aylık getirilerdeki (rtn_prior $12 \mathrm{~m}$ ) bir artışın pozitif değerlendirildiğ görülmektedir. 48 aylık değişkenler hiçbir modelde anlamlı değildir, yatırımcıların beklentileriyle ilgili olarak en fazla 36 aylık getiriler anlaml bulunmuştur. Barberis (2000) de beklenen hisse getirilerindeki şokların, gerçekleşen hisse getirileriyle negatif korelasyonu olduğunu göstermektedir.

\section{SONUÇ}

Geçmişte kazanan yatırımcıların portföy beklentileri, hisse beklentileriyle, geçmişte kaybeden yatırımcıların portföy ve hisse beklentileri arasında anlamlı bir fark olduğunu ortaya çıkmıştır. Geçmişte kazanan 
yatırımcılar gelecekle ilgili çok daha iyimserdir. Rasyonel yatırımcıların arasında bu farklılıkların olmaması gerekirdi ve ortaya çıkan farklılıkları sadece risklerin farklı oluşuyla açıklamak zordur. Tüm yatırımcılar rasyonel ya da bilgisiz değildir. Geçmişte her ne olursa olsun, bu durumun yatırımcıların beklentilerini etkilememesi beklenirdi ancak pozitif ya da negatif anlamda olsun, yatırımcıların geçmiş tecrübelerinin etkisi altında oldukları yorumuna varılabilir. Geçmişte kaybetmiş olan ancak iyimserliklerini koruyan yatırımcılara göre geçmişte kazanan yatırımcıların beklentileri arasında anlamlı bir fark bulunmuştur. Buna göre, kaybeden yatırımcılar iyimserliklerini korumaktadır ancak, kazanan yatırımcılar çok daha fazla iyimserdirler ve daha çok kazanacaklarına kanaat getirmişlerdir.

Yatırımcıların kendi tecrübelerine bu denli güvenmelerinin altında bunu destekleyen bazı psikolojik olgular vardır. Geçmiş tecrübelerden etkilenme (past extrapolation), aşırı güven (overconfidence) ve bu güveni oluşturan unsurlardan, kendine yorma yanlılığ 1 (self-attribution bias), bilgi illüzyonu, kontrol illüzyonun etkisinden söz edilebilir. Tarihsel olarak yatırımcıların aşırı iyimserliği de bilinen bir durumdur.

Yatay kesit olarak yapılan tüm analizler, bir kez de ortalama değerlere sıkıştırılarak (collapse) analiz edilmiştir. Araştırmanın açıklayıcı gücünü artırmak için uygulanan bu yöntemle bazı farklı sonuçlara ulaşılmıştır. Temel göstergelerin, yatırımcıların hisse beklentileri ile tek tek ilişkili olduğu bulgulanmıştır. Yatırımcıların hisse beklentileri ile geçmiş piyasa getirileri, geçmiş zamanlı kâr payı fiyat ve fiyat kazanç oranları, geçmiş faiz oranları, tüketici güven endeksi gibi göstergeler arasında farklı ağırlıklarda ilişkiler ve etkileşim vardır.

Yatırımcıların, çok da geri gitmeyen bir veri setinden yararlandıkları bilinen bir psikolojik gerçektir nitekim bu sebeple araştırmada en küçük zaman diliminden, sofistike sayılabilecek 48 aya kadar uzanan bir getiri değişkenleri seti kullanılmıştır. 48 aylık değişken hiçbir modelde anlamlı sonuç vermemiştir ki bu durum önermeyi destekler bir durumdur. Çok küçük bir örneklem setinden, fazla geri gitmeyen bir veri seti kullanmak rasyonel değildir ancak görülmektedir ki özelikle sadece geçmiş bir yılın getirilerinden oldukça yüksek oranda etkilenmekte, gelecek beklentilerinin mesnedi yapmaktadırlar.

Vissing-Jorgensen'in (2003) daha önce çalışmasında aynı veri seti ile yapmış olduğu analiz, genişletilerek tekrarlanmış, aynı sonuçlara hem yatay kesit hem de ortalamalarla ulaşılmış yani geçmiş getirilerin gelecekteki beklentileri etkilediği ortaya konmuştur. Geçmiş tecrübelerin etkisinin " 0 " olması etkin piyasalar hipotezine göre şarttır. Hâlbuki yatırımcılar etkin piyasa hipotezinin aksine beklentiler üzerinde geçmiş getirilerin çok güçlü bir etkisi vardır. Buna göre; geçmiş tecrübelerin etkisinden (past extrapolation) söz edilebilir.

Son olarak, tüm faktörlerin aynı anda modele konmasıyla birlikte ilave faktörlerin yatırımcıların kendi geçmiş getirilerinin etkisini azaltıp azaltmayacağını araştırılmıştır. Yatırımcılar her ne kadar diğer faktörlere farklı 
farklı ağırlıklar da verseler, hem yatay kesit, hem ortalamalarla kurulan modellere göre geçmiş getirilerin etkisini ortadan kaldıramamakta hatta etkisini ve ağırlığını azaltamamaktadir.

\section{KAYNAKÇA}

Amromin, G., \& Sharpe, S. a. (2009). Expectations of Risk and Return among Household Investors: Are their Sharpe Ratios Countercyclical? Board of Governors of the Federal Reserve System Working Paper, 1-43. Retrieved from http://ezproxy.lib.monash.edu.au/login?url=http://search.ebscohost.com/login.aspx?direct $=$ true $\& \mathrm{db}=\mathrm{bth} \& \mathrm{AN}=35912536 \&$ site $=$ ehost-live $\&$ scope $=$ site

Barber, B. M., \& Odean, T. (2002). Online Investors: Do the Slow Die First? Review of Financial Studies, 15(2), 455-487. http://doi.org/10.2139/ssrn.219242

Benos, A. V. (1998). Aggressiveness and survival of overconfident traders. Journal of Financial Markets, 1(3-4), 353-383. http://doi.org/10.1016/S1386-4181(97)00010-4

Bondt, D., F.M, W. (1998). A portrait of the individual investor. European Economic Review, 42(35), 831-844. http://doi.org/10.1016/S0014-2921(98)00009-9

Bondt, D., F. M. W., \& Thaler, R. (1985). Does the Stock Market Overreact? Journal of Finance, 40(3), 793-805. http://doi.org/10.1111/j.1540-6261.1985.tb05004.x

Caballé, J., \& Sákovics, J. (2003). Speculating against an overconfident market. Journal of Financial Markets, 6(2), 199-225. http://doi.org/10.1016/S1386-4181(01)00030-1

Daniel, K., Hirshleifer, D., \& Teoh, S. H. (2002). Investor psychology in capital markets: evidence and policy implications. Journal of Monetary Economics, 49(1), 139-209. http://doi.org/10.1016/S0304-3932(01)00091-5

Daniel, K. D., Hirshleifer, D., \& Subrahmanyam, A. (1998). Investor Psychology and Security Market Under- and Overreactions. Journal of Finance, 53(6), 1839-1886. http://doi.org/10.2307/117455

Daniel, K. D., Hirshleifer, D., Berk, J., Brennan, M., Ferson, W., Jones, B., ... Spiegel, M. (2001). Overconfidence, Arbitrage, and Equilibrium Asset Pricing. Journal of Finance, LVI(3), 921-965. http://doi.org/10.1111/0022-1082.00350

Darrough, M. N., \& Russell, T. (2002). A positive model of earnings forecasts: top down versus bottom up. Journal of Business, 75(1), 127-152. doi: 10.1086/323507

Dominitz, J., \& Manski, C. F. (2003). How should we measure consumer confidence (sentiment)? Evidence from the Michigan Survey of Consumers(No. w9926). National Bureau of Economic Research. http://www.nber.org/papers/w9926

Dominitz, J., \& Manski, C. F. (2004). How should we measure consumer confidence? Journal of Economic Perspectives, 51-66. http://www.jstor.org/stable/3216890.

Dominitz, J., \& Manski, C. F. (2011). Measuring and interpreting expectations of equity returns. Journal of Applied Econometrics, 26(November 2010), 352-370. http://doi.org/10.1002/jae.1225

Eames, M., S. Glover, and J. Kennedy (2000). The association between trading recommendations and broker-analysts' earnings forecasts. University of Washington, Working Paper içinde Daniel, K., Hirshleifer, D., Teoh, SW., (2002). Investor Psychology in Capital Markets: Evidence and Policy Implications. Journal of Monetary Economics, Volume 49, Issue 1, ,Pages 139-209. doi:10.1016/S0304-3932(01)00091-5

Elliott, W. B., Hodge, F. D., \& Jackson, K. E. (2008). The Association between Nonprofessional Investors' Information Choices and Their Portfolio Returns: The Importance of Investing Experience. Contemporary Accounting Research, 25(2), 473-498. http://doi.org/10.1506/car.25.2.7

Fisher, K. L., \& Statman, M. (2002). Blowing Bubbles. Journal of Psychology and Financial Markets, 3(1), 53-65. http://doi.org/10.1207/S15327760JPFM0301_08

Gervais, S., \& Odean, T. (2001). Learning To Be Overconfident. The Review of Financial Studies, 14(1), 1-27. http://doi.org/10.2139/ssrn.36313 
Griffin, D., \& Tversky, A. (1992). The weighing of evidence and the determinants of confidence. Cognitive Psychology, 24(3), 411-435. http://doi.org/10.1016/0010-0285(92)90013-R

Kahneman, D., \& Riepe, M. W. (1998). Aspects of investor psychology. The Journal of Portfolio Management, 24(4), 52-65. doi: 10.3905/jpm.1998.409643

Kyle, A. S., \& Wang, F. A. (1997). Speculation Duopoly with Agreement to Disagree: Can Overconfidence Survive the Market Test? Journal of Finance, 52(5), 2073-2090. http://doi.org/10.2307/2329474

Lintner, J. (1965). The valuation of risk assets and the selection of risky investments in stock portfolios and capital budgets. The review of economics and statistics, 13-37. http://doi.org/10.2307/1924119

Lintner, J. (1969). The aggregation of investor's diverse judgments and preferences in purely competitive security markets. Journal of Financial and Quantitative Analysis, 4(04), 347400. doi:10.2307/2330056.

Long, J. B. De, Shleifer, A., Summers, L. H., \& Waldmann, R. J. (1991). The Survival of Noise Traders in Financial Markets. The Journal of Business, 64(1), 1. http://doi.org/10.1086/296523

Manski, C. F. (2004). Measuring expectations. Econometrica, 72(5), 1329-1376. http://doi.org/10.1111/j.1468-0262.2004.00537.x

Nofsinger, J. R. (2010). The psychology of investing. Pearson Prentice Hall.,isbn: 0-13-611703, Fourth edition

Odean, T. (1998). Volume, Volatility, Price, and Profit When All Traders Are Above Average. The Journal of Finance, 53(6), 1887-1934. http://doi.org/10.1111/0022-1082.00078

Rothman, A. J., \& Hardin, C. D. (1997). Differential use of the availability heuristic in social judgment. Personality and Social Psychology Bulletin,23(2), 123-138.

Rublin, Lauren R.,(1997, 23 Haziran). Another chance, Barron's Magazine

Sharpe, W. F. (1964). Capital Asset Prices: A Theory of Market Equilibrium under Conditions of Risk. The Journal of Finance, 19(3), 425-442. http://doi.org/10.2307/2329297

Sharpe, W. F. (1970). Portfolio theory and capital markets. McGraw-Hill College.

Shefrin, H. (2002). Beyond greed and fear: Understanding behavioral finance and the psychology of investing. Oxford University Press.

Thaler, R. H. (1987). Anomalies: The January Effect. Journal of Economic Perspectives, 1(1), 197201. http://doi.org/10.1257/jep.1.1.197

Tversky, A. \& Kahneman, D. (1973). Availability: A heuristic of Judging Frequency and Probability. İçinde, D.Kahneman, P.Slovic and A.Tversky (1982). Judgement Under Uncertainity: Heuristics and Biases, Cambridge: Cambridge University Press, pp.1634, 1982 doi:10.1016/0010-0285(73)90033-9

Tversky, a, \& Kahneman, D. (1974). Judgment under Uncertainty: Heuristics and Biases. Science (New York, N.Y.), 185(4157), 1124-1131. http://doi.org/10.1126/science.185.4157.1124

Vissing-Jorgensen, A. (2003). Perspectives on Behavioral Finance: Does "Irrationality" Disappear with Wealth? Evidence from Expectations and Actions. SSRN Electronic Journal (Vol. 18). http://doi.org/10.2139/ssrn.417421

\section{SUMMARY}

Traditional finance theories tend to ignore investor behaviours mostly. The financial markets operate like a machine system under rationality. Many empirical evidences prove that markets do not work efficiently and investors are not rational. The traditionalists explained the market anomalies by unsophisticated investor behaviours and suggest that such behaviours cannot 
affect the market and market forces correct such anomalies immediately and eliminate irrational investors. However, the arbitrage opportunity is limited and risky, in addition psychological biases and heuristics cause systematic outrays from rationality has been documented in the field of behavioural finance. A judgement problem such as overoptimism causes a twist in beliefs and overconfidence causes excessive trade and increase self-attribution. Investors are expected to form their return expectations rationally which can be predicted as traditional theories suggest. The original CAPM (Capital Asset Pricing Model) assumes all investors should expect the same returns and the heterogeneity in expectations has no effect on the model. Some researchers show the heterogeneity matters. Sex, age and education affect stock return expectations constantly. The question how investors form their expectations, is not clearly find response.

UBS/Gallup Investor Optimism dataset, Standard and Poors 500 total returns, Robert Shiller's Earnings and dividends dataset, Michigan Consumer Sentiment Index, and interest rates are used. UBS/Gallup Investor Optimism Survey was conducted only for four years, then stopped because the survey faced with accuses for affecting markets. The responses about the percentage returns from their own portfolio in last 12 months and return expectations for next 12 months and the stock market expectations are used as variables. In order to determine if there are any other information factors affect expectations; S\&P 500 returns and dividends are calculated by different methods and time intervals. Ttests, F-tests, Regressions are performed with post-hoc tests such as multicollinearity.

The expectations of investors who had higher returns in the past is significantly differ from investors who experienced losses. In addition, there is a significant difference between the past losers' who are optimistic and past winners. There should be no difference if the investors were forming their expectations rationally. The past losers keep their optimism but past winners are expecting much more than them.

There should not be any sign of forming expectations formed by previous returns. Same methodology that Vissing-Jorgensen performed is widened and used. We achieved the same results that show past returns affect future expectations. The past returns and future return expectations tested with outdate financial indicators. All variables are correlated with the expectations in crosssection and collapsed variables. Three models are developed for different return calculations. In Model 1, the stock return expectations are dependent variable and independent variables; past stock returns - interest rate - CSI and past 1 month dividend yield, past 3 months earnings yield, last 12 and 36 months stock returns are significantly related to stock return expectations. Model 2, the stock return expectations are dependent variable and independent variables; past stock returns - interest rate - CSI and past 12 months dividend yield, 1 month earnings yield, 12 months earnings yield, average returns prior to 12 months, two years average returns are significantly related to stock return expectations. In the third model, all 
observations in cross-section dataset are collapsed into scores and the same models are applied and find that past stock returns, interest rates 3 months earnings yield, last 12 and 36 months average returns has significantly associated with future stock return expectations. As a result, investors are not rational as traditional theory suggests. 